\title{
Association between polyunsaturated fatty acid-derived oxylipid biosynthesis and leukocyte inflammatory marker expression in periparturient dairy cows
}

\author{
W. Raphael, L. Halbert, G. A. Contreras, and L. M. Sordillo ${ }^{1}$ \\ College of Veterinary Medicine, Michigan State University, East Lansing 48824
}

\begin{abstract}
Peripheral blood mononuclear leukocytes from periparturient cows can have exacerbated inflammatory responses that contribute to disease incidence and severity. Oxylipids derived from the oxygenation of polyunsaturated fatty acids (PUFA) can regulate the magnitude and duration of inflammation. Although PUFA substrate for oxylipid biosynthesis in leukocytes is known to change across the periparturient period, the plasma oxylipid profile and how this profile relates to leukocyte inflammatory phenotype is not clear. The objective of this study was to determine if a relationship exists between the profile of pro- and antiinflammatory plasma oxylipids and the inflammatory phenotype of peripheral blood leukocytes during the periparturient period. Seven multiparous Holsteins were sampled from the prepartum period through peak lactation. Plasma oxylipids were measured by liquid chromatography-mass spectrometry, peripheral leukocyte mRNA expression was measured by quantitative PCR, and PUFA content of peripheral blood mononuclear cells was measured by gas chromatography-mass spectrometry. Concentrations of several hydroxyl products of linoleic and arachidonic acid changed over time. Linoleic acid and arachidonic acid concentrations in leukocytes increased during early lactation, suggesting that substrate availability for hydroxyoctadecadienoic and hydroxyeicosatetraenoic acid biosynthesis may influence the oxylipid profile. Leukocyte mRNA expressions of $I L-12 B, I L-1 B$, inducible nitric oxide synthase 2 , and cyclooxygenase 2 were correlated with several plasma oxylipids. These are the first observations linking leukocyte inflammatory gene responses to shifts in oxylipid biosynthesis in periparturient dairy cows.
\end{abstract}

Key words: inflammation, periparturient, eicosanoid, oxylipid, lipid mediator

Received October 30, 2013.

Accepted February 25, 2014.

${ }^{1}$ Corresponding author: sordillo@msu.edu
INTRODUCTION

A major factor contributing to decreased productivity and longevity of dairy cows is the incidence of disease in the first month after parturition (Pinedo et al., 2010). Dysfunctional inflammatory responses during the periparturient period can contribute to disease incidence and severity (Sordillo and Raphael, 2013). For example, bovine peripheral blood mononuclear cells (PBMC) have an exacerbated inflammatory response to LPS in the periparturient period, compared with cells from mid-lactation cows (Sordillo et al., 1995). Uncontrolled inflammatory responses also were associated with increased severity of clinical mastitis (Shuster et al., 1996). Control and prevention of periparturient disease is currently difficult, partly because it is unclear why dysfunctional inflammatory responses occur around parturition.

Oxylipids are defined as the class of PUFA-derived metabolites that regulate all aspects of the inflammatory response. The biosynthesis of oxylipids involves several complex pathways that start with the peroxidation of cell membrane-derived PUFA, including linoleic (C18:2n-6), arachidonic (C20:4n-6), eicosapentaenoic (C20:5n-3), and docosahexaenoic acids (C22:6n-3). Initial peroxidation of these PUFA can occur enzymatically through the cyclooxygenases (COX), lipoxygenases (LOX), and epoxygenases, but are also mediated by free oxygen radicals. Oxylipids produced by PUFA peroxidation include 9- and 13-hydroperoxyoctadecadienoic acid (HPODE), prostaglandin (PG) $\mathrm{H}_{2}, 5$ - and 15-hydroperoxyeicosatetraenoic acids, and 14- and 17-hydroperoxydocosahexaenoic acids (Serhan and Petasis, 2011; Smith et al., 2011). These are unstable lipid mediators that are quickly reduced to more stable hydroxyls, such as hydroxyoctadecadienoic acid (HODE) and hydroxyeicosatetraenoic acid (HETE). The hydroxyl oxylipids can serve as substrates to a vast number of downstream metabolites, such as oxooctadecadienoic acids (OxoODE; Ramsden et al., 2012), leukotrienes (LT; Nakamura and Shimizu, 2011), thromboxanes (TX), $\mathrm{PGD}_{2}, \mathrm{PGE}_{2}, \mathrm{PGF}_{2}, \mathrm{PGI}_{2}$ (Smith et al., 2011), 7-maresin 1 (MaR1), and protectins (PD; Serhan and Petasis, 2011). Thus, the rate 
of PUFA oxidation and the extent of metabolism into downstream products determine the relative abundance of oxylipids with different functional capabilities.

A major determinant of whether oxylipids initiate or resolve inflammation is the PUFA from which they are derived. Both C20:5n-3- and C22:6n-3-derived oxylipids predominantly abrogate inflammation. For example, MaR1 is produced from $\mathrm{C} 22: 6 \mathrm{n}-3$ and reduces neutrophil recruitment during peritoneal inflammation (Serhan et al., 2009). In contrast to the n-3 PUFAderived oxylipids, the downstream products of $n-6$ PUFA peroxides have multiple effects in inflammatory pathways. Different PG, for example, can stimulate (e.g., $\mathrm{PGF}_{2}$ ) or abrogate (e.g., $\mathrm{PGD}_{2}$ and $\mathrm{PGE}_{2}$ ) inflammatory events (Serhan et al., 2008). The effects of some n-6-derived oxylipids are dependent on species and cell types. For example, HODE activates adhesion molecule expression on endothelial cells (Friedrichs et al., 1999), thus facilitating leukocyte extravasation during inflammation. However, HODE also binds to nuclear receptors, and abrogates tumor necrosis factor $\alpha$ (TNF- $\alpha)$-induced inflammatory responses in human epithelial tissue (Altmann et al., 2007). Several studies showed that dietary changes in PUFA substrate supply could effectively change oxylipid profiles. (Raphael and Sordillo, 2013). For example, n-3 PUFA dietary supplementation in humans and rodents was shown to increase tissue phospholipid content of these PUFA and increase n-3 PUFA-derived oxylipids in tissue (Poulsen et al., 2008; Ramsden et al., 2012). Recent studies in periparturient dairy cows identified C18:2n-6 as more abundant in several tissues after parturition, including PBMC (Contreras et al., 2010; Akbar et al., 2013), but the influence of $\mathrm{C} 18: 2 \mathrm{n}-6$ on oxylipid production and leukocyte inflammatory pathways in cows is not known.

Concentrations and relative potency of individual oxylipids (Nagy et al., 1998; Norling et al., 2012) determine the net effect of the tissue oxylipid profile on inflammatory processes. The abundance of proinflammatory oxylipids relative to proresolving oxylipids affects the chronicity and resolution of disease by initiating or resolving segments of the inflammatory pathway (Serhan and Petasis, 2011). Describing the plasma concentrations of oxylipids in periparturient cows, in particular those oxylipids that may affect circulating immune cells and vascular endothelium, may assist in explaining why periparturient PBMC may have enhanced inflammatory responses following exposure to bacterial agonists (Sordillo et al., 1995). The hypothesis of the current study was that a relationship exists between the profile of pro- and antiinflammatory plasma oxylipids and the inflammatory phenotype of peripheral blood leukocytes during the periparturient period.

\section{MATERIALS AND METHODS}

\section{Animals}

This study was conducted in the autumn months of 2012 in a 1,500-cow, intensively housed commercial dairy herd located in Michigan. The herd was fed TMR that contained corn silage and alfalfa haylage as predominant forages. Seven Holstein cows were randomly selected from all healthy cows within 8 to $12 \mathrm{~d}$ of expected parturition at study commencement. The median parity for the observed parturition was 3, and ranged from 2 to 4 . Blood (50 mL) was aseptically collected in EDTA Vacutainers (Becton, Dickinson and Co., Franklin Lakes, NJ) by coccygeal venipuncture, and immediately stored on ice. The distribution of sampling time relative to parturition was $14 \mathrm{~d}$ prepartum (range $=6$ to $17 \mathrm{~d}$ ), immediately after parturition (range $=$ 1 to $3 \mathrm{~d}$ postpartum), $10 \mathrm{~d}$ postpartum (range $=7$ to $10 \mathrm{~d}$ ), $28 \mathrm{~d}$ postpartum (range $=21$ to $32 \mathrm{~d}$ ), and $84 \mathrm{~d}$ postpartum (range $=77$ to $88 \mathrm{~d}$ ). Plasma NEFA were measured in 3 randomly selected cows by an enzymatic colorimetric method [Wako NEFA HR(2); Wako Chemicals USA, Richmond, VA] conducted at the Diagnostic Center for Population and Animal Health (Lansing, MI). The Michigan State University Animal Care and Use Committee preapproved all animal use and care.

\section{Plasma Oxylipid Quantification}

Oxylipid Extraction. Plasma $(500 \mu \mathrm{L})$ was separated from whole blood before PBMC isolation (centrifugation at $931 \times g$ for $30 \mathrm{~min}$ at $4^{\circ} \mathrm{C}$ ). Formic acid $(1.7 \mu \mathrm{L})$ and antioxidant/reducing agents were added [ $4 \mu \mathrm{L}$ of combined $2.4 \mathrm{mg}$ of EDTA in $3 \mathrm{~mL}$ of water, $2.4 \mathrm{mg}$ of butylated hydroxytoluene (BHT) in 1.5 $\mathrm{mL}$ of ethanol, $24 \mathrm{mg}$ of triphenylphosphine in $6 \mathrm{~mL}$ of methanol (Sigma-Aldrich, St. Louis, MO), and 24 $\mathrm{mg}$ of indomethacin in $1.5 \mathrm{~mL}$ of ethanol (Cayman Chemical Co., Ann Arbor, MI)]. Deuterated internal standards $\quad\left[\mathrm{LTB}_{4}-\mathrm{d}_{4}, \quad \mathrm{TXB}_{2}-\mathrm{d}_{4}, \quad \mathrm{PGF}_{2 \alpha}-\mathrm{d}_{4}, \quad \mathrm{PGE}_{2}-\mathrm{d}_{4}\right.$, $\mathrm{PGD}_{2}-\mathrm{d}_{4}, \quad$ 13(S)-HODE- $\mathrm{d}_{4}$, 6-keto $\mathrm{PGF}_{1 \alpha}-\mathrm{d}_{4}$, 12(S)HETE- $\mathrm{d}_{8}$, and 15(S)-HETE- $\mathrm{d}_{8}$; Cayman Chemical Co.] were combined in ethanol:water (1:1), to achieve $0.1 \mathrm{ng} / \mu \mathrm{L}$ for each standard, and $200 \mu \mathrm{L}$ of this mixture (20 ng of each standard) was added to samples. Methanol was then added to samples $\left(1 \mathrm{~mL} ;-20^{\circ} \mathrm{C}\right)$, and protein precipitated by brief vortexing and freezing $\left(-20^{\circ} \mathrm{C}\right.$ for $\left.3 \mathrm{~h}\right)$. Samples were then centrifuged at $18,000 \times g$ for $15 \mathrm{~min}$ at $4^{\circ} \mathrm{C}$. The supernatant was diluted in $9.2 \mathrm{~mL}$ of water containing $0.1 \%$ formic acid (vol/vol). Oxylipids were extracted by solid-phase methods as previously reported (Farney et al., 2013), with the following modifications. Extraction columns 
(Strata-X $60 \mathrm{mg}, 3 \mathrm{~mL}$; Phenomenex Inc., Torrance, $\mathrm{CA})$ were conditioned $(3 \mathrm{~mL}$ of methanol and then 3 $\mathrm{mL}$ of water), washed $[3 \mathrm{~mL}$ of $50 \%$ methanol (vol/vol) in HPLC-grade water], dried, and samples eluted in $3 \mathrm{~mL}$ of methanol:acetonitrile (1:1, vol/vol). Samples were then vacuum dried, suspended in $200 \mu \mathrm{L}$ of acetonitrile:water:formic acid (1,850:3,150:1, vol/vol/ $\mathrm{vol})$, and centrifuged at $18,000 \times g$ for $30 \mathrm{~min}\left(4^{\circ} \mathrm{C}\right)$, immediately before chromatography.

Liquid Chromatography-Mass Spectrometry. Oxylipids were measured using liquid chromatographymass spectrometry as we reported previously (Farney et al., 2013) but with quantification of 8-iso- $\mathrm{PGF}_{2 \alpha}$, $\mathrm{PGE}_{2}, \mathrm{PGD}_{2}, \mathrm{PGF}_{2 \alpha}, \mathrm{TXB}_{2}$, 6-keto $\mathrm{PGF}_{1 \alpha}$, resolvin $\mathrm{D}_{1}$, and resolvin $\mathrm{D}_{2}$ using an isocratic mobile phase of acetonitrile:water:0.1\% formic acid (35:55:10, vol/ vol/vol). 9-Hydroxyoctadecadienoic acid, 13-HODE, 15-oxoeicosatetraenoic acid, 5-oxoeicosatetraenoic acid, 5-hydroxyeicosatetraenoic acid (HETE), 8-HETE, 11HETE 12-HETE, 15-HETE, 20-HETE, 9-OxoODE, 13-OxoODE, MaR1, PD1, and $\mathrm{LTD}_{4}$ were measured as previously described (Farney et al., 2013). Oxylipids were identified in samples by matching their deprotonated (i.e., $[\mathrm{M}-\mathrm{H}]-) \mathrm{m} / z$ values and $\mathrm{LC}$ retention times with those of pure standards. Oxylipids were quantified relative to internal standard abundance, and calibration against standard curves.

\section{PBMC FAME Quantification}

Lipid Extraction. Peripheral blood mononuclear cells in $45 \mathrm{~mL}$ of whole blood were isolated using a Ficoll-Paque Plus gradient (GE Healthcare, Waukesha, WI), as previously described (Contreras et al., 2010). Pelletized PBMC were frozen in liquid nitrogen and stored at $-80^{\circ} \mathrm{C}$ until completion of sample collections. Total lipid was extracted using methanol and chloroform, as previously reported (Folch et al., 1957; Bligh and Dyer, 1959). Briefly, PBMC pellets were suspended in $1.0 \mathrm{~mL} 1 \times \mathrm{PBS}$ and then proteins were precipitated by adding $3.0 \mathrm{~mL}$ of $-20^{\circ} \mathrm{C}$ methanol ( 500 $\mathrm{mg}$ of BHT/L). After $30 \mathrm{~min}, 1.0 \mathrm{~mL}$ of $1 \times \mathrm{PBS}, 2.0$ $\mathrm{mL}$ of methanol $(500 \mathrm{mg}$ of $\mathrm{BHT} / \mathrm{L}), 7.0 \mu \mathrm{L}$ of formic acid, and $7.5 \mu \mathrm{g}$ of C13:0 FA (1 mg/mL of hexane) were added. Samples were then sonicated $\left(30 \mathrm{~min}\right.$ at $\left.25^{\circ} \mathrm{C}\right)$, and $2.5 \mathrm{~mL}$ of chloroform was added. Samples were then shaken for $16 \mathrm{~h}\left(25^{\circ} \mathrm{C}\right)$, and a further $2.5 \mathrm{~mL}$ of chloroform and $2.5 \mathrm{~mL}$ of $2 \%$ sodium chloride (wt/vol, in HPLC-grade water) were added. Following centrifugation $\left(2,095 \times g\right.$ for 15 min at $\left.8^{\circ} \mathrm{C}\right)$, chloroform was aspirated and stored, and extraction repeated with 2.5 $\mathrm{mL}$ of chloroform and centrifugation at 2,095 $\times \mathrm{g}$ for 15 min at $8^{\circ} \mathrm{C}$. Samples were then dried under vacuum.
Contaminant lipids were measured in cell-free samples, concurrent with PBMC samples.

Derivation. Sample lipids were saponified in 0.5 $\mathrm{mL}$ of methanol, using $1.0 \mathrm{~mL}$ of freshly made $0.5 \mathrm{M}$ potassium hydroxide in methanol, and heat $\left(100^{\circ} \mathrm{C}\right.$ for $10 \mathrm{~min}$ ). After cooling to $4^{\circ} \mathrm{C}$, derivation of PUFA to methyl esters (FAME) was performed under nitrogen gas, using $3.0 \mathrm{~mL}$ of fresh $20 \%$ (vol/vol) methanolic hydrochloric acid (Palmquist and Jenkins, 2003), and heat $\left(90^{\circ} \mathrm{C}\right.$ for $\left.16 \mathrm{~h}\right)$. After cooling to $4^{\circ} \mathrm{C}$, acid was neutralized using $10.0 \mathrm{~mL}$ of $6 \%$ potassium carbonate (wt/vol, in HPLC-grade water). Fatty acid methyl esters were then extracted with $3.0,1.5$, and $1.5 \mathrm{~mL}$ $n$-hexanes by centrifugation $\left(524 \times g\right.$ for 5 min at $\left.8^{\circ} \mathrm{C}\right)$. Samples were then vacuum dried, resuspended in $35 \mu \mathrm{L}$ of $n$-hexanes, and transferred to a GC microinsert vial. Finally, $7.5 \mu \mathrm{g}$ of C15:0 FAME ( $5 \mathrm{mg} / \mathrm{mL}$ of hexane) was added, and samples immediately analyzed by GCMS.

$\boldsymbol{G C}-\boldsymbol{M S}$. The gas chromatograph was Agilent Technologies model 6890N (Agilent Technologies Inc., Santa Clara, CA), fitted with a DB-23 column $(30 \mathrm{~m} \times 0.25-$ $\mathrm{mm}$ i.d. $\times 0.25$-um film thickness; Agilent Technologies Inc.). The inlet temperature was $240^{\circ} \mathrm{C}$. The method used helium gas at $60.2 \mathrm{kPa}$, a $20: 1$ split ratio, and a combined flow rate of $25.9 \mathrm{~mL} / \mathrm{min}$. The column temperature was optimized and set at $50^{\circ} \mathrm{C}$ for $1 \mathrm{~min}$, which was then increased at $25^{\circ} \mathrm{C} / \mathrm{min}$ to $175^{\circ} \mathrm{C}$, and then increased at $4^{\circ} \mathrm{C} / \mathrm{min}$ to $240^{\circ} \mathrm{C}$ and held constant for $5 \mathrm{~min}$. The total run time was $27.25 \mathrm{~min}$. The injection volume was $1.0 \mu \mathrm{L}$. A pre- and postinjection delay of $1 \mathrm{~s}$ was applied.

The mass spectrometer was Agilent Technologies model 5975B inert XLMSD (Agilent Technologies Inc.). The transfer line, source, and quadrupole temperatures were 240,230 , and $150^{\circ} \mathrm{C}$, respectively. Detection criteria were 40 to $400 \mathrm{amu}$, and a 3-min solvent delay was applied. Total ion chromatograms and mass spectra were generated using Agilent ChemStation software (Agilent Technologies Inc.). A 37-component FAME standard mix was used to determine retention times (Sigma-Aldrich). Analytes were identified with at least 90\% similarity between analyte and reference mass spectra (National Institute of Standards and Technology, Gaithersburg, MD). Total ion chromatograms were created for FAME of C13:0, C15:0, C18:2n-6, and C20:4n-6. Extracted ion chromatograms were created for FAME of C15:0 (74 amu), C20:5 (79 amu) and $\mathrm{C} 22: 6$ (79 amu) at the appropriate retention times.

Gas chromatography-mass spectrometry was validated in several ways. The within-assay and between-assay coefficients of variation for standard grade C18:2 n6 FAME were calculated to be 5 and $15 \%$, respectively. 
Second, a single cow sample was divided into 3 aliquots and analyzed separately at the beginning, midway, and completion of chromatography. The coefficient of variation for C18:2n-6 to C15:0 FAME ratio across these 3 aliquots was $5.4 \%$. Finally, because chromatograms were performed in 2 batches, variance in chromatogram intensity of the C15:0 FAME internal standard between batches was assessed by calculating the ratio of intensity in samples to that of calibration standards for each batch $(\mathrm{CV}=0.9 \%)$. Batch variance in methylation efficiency was also evaluated and the coefficient of variation was $10.3 \%$.

FAME Quantification. Sample internal standards were added before extraction (C13:0 FA) and following derivation (C15:0 FAME). Calibration curves for C18:2n-6, C20:4n-6, C20:5n-3, and C22:6n-3, and C13:0 FAME were created using freshly prepared standardgrade FAME, analyzed before and after the samples. Standard dilutions were 0.7 fold in $n$-hexanes, and concentrations extended 2 dilutions above the maximum sample concentration and below the minimum sample concentration. Calibration equations were calculated by linear regression of the known standard concentration against the ratio of analyte to C15:0 FAME $\left(\mathrm{R}^{2}>\right.$ 0.98). This ratio was calculated from analyte and $\mathrm{C} 15: 0$ FAME chromatogram intensities.

The analyte concentration in samples was calculated by comparing the intensity ratio of analyte to C15:0 FAME in samples to that of the linear regression equation from calibration. Analyte concentrations in samples were corrected for methylation efficiency by comparing the C13:0 FAME abundance in samples to the expected abundance from C13:0 FA internal standard. Analyte concentrations also were corrected for FAME abundance in cell-free samples.

\section{Leukocyte mRNA Quantification by Quantitative PCR}

Total RNA was extracted from $3 \mathrm{~mL}$ of whole blood for quantification of mRNA using the QIAamp RNA Blood Mini Kit (Qiagen Inc., Valencia, CA) with DNase. Complementary DNA was synthesized using the High Capacity cDNA Reverse Transcription Kit with RNase Inhibitor (Applied Biosystems Inc., Foster City, CA). A single sample was excluded for poor RNA integrity (RNA integrity <6; Agilent Bioanalyzer; Agilent Technologies Inc.). Primers were derived from the Bos taurus genome (Table 1). The cDNA was amplified using TaqMan PreAmp Kit (Applied Biosystems Inc.). The quantitative PCR was conducted as previously reported (Contreras et al., 2012a). Briefly, PCR was performed in triplicate, using $20 \mu \mathrm{L}$ of reaction mixture per replicate, comprising $11.7 \mu \mathrm{L}$ of TaqMan Gene Expression PCR Master Mix (2×; Applied Biosystems
Inc.), $1.2 \mu \mathrm{L}(20 \times)$ of TaqMan Gene Expression Assay Mix (Applied Biosystems Inc.), $5 \mu \mathrm{L}$ of amplified cDNA, and $2.1 \mu \mathrm{L}$ of nuclease-free water. Pre-designed $(20 \times)$ TaqMan Gene Expression Assays from Applied Biosystems Inc. for bovine TATA box binding protein $(T B P)$, phosphoglycerate kinase $(P G K 1)$, and $\beta$-actin $(A C T B)$ were selected as reference genes. Each PCR plate included a nontemplate control. Two-step PCR thermal cycling conditions were used: stage $1: 50^{\circ} \mathrm{C}$ for $2 \mathrm{~min}$, stage $2: 95^{\circ} \mathrm{C}$ for $10 \mathrm{~min}$, stage $3: 95^{\circ} \mathrm{C}$ for 15 $\mathrm{s}$, and stage $4: 60^{\circ} \mathrm{C}$ for $1 \mathrm{~min}$, with 40 replicates of stages 3 and 4. Quantification was carried out with the relative quantification method (Livak and Schmittgen, 2001). Briefly, the abundance of target genes is normalized to the average of the reference genes, and calculated relative to calibrator samples by $2^{-\Delta \Delta \mathrm{Ct}}$, where $\mathrm{Ct}$ is the cycle number at which the fluorescence signal of the product crosses an arbitrary threshold set with exponential phase of the PCR, and $\Delta \Delta \mathrm{Ct}=\left(\mathrm{Ct}_{\text {target }}\right.$ gene unknown sample $-\mathrm{Ct}_{\text {average of endogenous control genes unknown sample) }}$ ) - $\left(\mathrm{Ct}_{\text {target gene calibrator sample }}-\mathrm{Ct}_{\text {average of endogenous control genes }}\right.$ calibrator sample). Samples collected at $84 \mathrm{~d}$ were the calibrator samples.

\section{Statistical Evaluation}

Temporal oxylipid, mRNA (mean $\Delta \mathrm{Ct}$ ), and FAME concentrations were evaluated in a mixed ANOVA model, with cow as a random source of variance, the dependent variables repeated across time and within cow, and the model solved for the fixed effect of time. Covariance structures (compound symmetry, unstructured, or first-order autoregressive) were selected according to the Akaike information criterion. Differences between least squares means were calculated with the Šidák adjustment. Pearson correlations were calculated to measure associations between plasma oxylipid concentrations and leukocyte mRNA expression (23 oxylipids $\times 8$ genes $=184$ correlations), and between PBMC PUFA and plasma oxylipid concentrations (3 PUFA $\times 23$ oxylipids $=69$ correlations), and between PBMC PUFA concentrations and leukocyte mRNA expression ( 3 PUFA $\times 8$ genes $=24$ correlations $)$. Mean $\Delta$ Ct was multiplied by -1 before calculation of Pearson coefficients. Significance of correlation was adjusted for false discovery associated with multiple tests.

\section{RESULTS}

\section{Animal Production and Health}

All cows remained free from clinical disease during the period of study. Mean ( \pm SD) 305-d mature-equivalent milk production was $12,324( \pm 2,518) \mathrm{kg}$. Mean $( \pm \mathrm{SE})$ 
Table 1. Gene targets for quantitative PCR

\begin{tabular}{lll}
\hline Gene $^{1}$ & $\begin{array}{l}\text { Reference } \\
\text { sequence }^{2}\end{array}$ & $\begin{array}{l}\text { TaqMan assay } \\
\text { identification }\end{array}$ \\
\hline$I L-10$ & NM_174088.1 & Bt03212724_m1 \\
$I L-12 B$ & NM_174356.1 & Bt03213923_m1 \\
NOS2 & NM_001076799.1 & Bt03249598_m1 \\
$I L-1 \beta$ & NM_174093.1 & Bt03212741_m1 \\
$T N F-\alpha$ & NM_173966.3 & Bt03259156_m1 \\
$15-L O X 1$ & NM_174501.2 & Bt03214775_m1 \\
$C O X 2$ & NM_174445.2 & Bt03214492_m1 \\
$H P G D$ & NM_001034419.2 & Bt03226254_m1 \\
$T B P^{4}$ & NM_001075742.1 & Bt03241946_m1 \\
$P G K 1^{4}$ & NM_173979.3 & Bt03225857_m1 \\
$A C T B^{4}$ & Bt03279174_g1
\end{tabular}

${ }^{1}$ NOS2 = inducible nitric oxide synthase $2 ; T N F-\alpha=$ tumor necrosis factor $\alpha ; 15-L O X 1=15$-lipoxygenase 1; $C O X 2=$ cyclooxygenase $2 ; H P G D=15$-hydroxyprostaglandin dehydrogenase; $T B P=$ TATA box binding protein; $P G K 1=$ phosphoglycerate kinase; $A C T B=\beta$-actin.

${ }^{2}$ National Center for Biotechnology Information (Bethesda, MD) reference sequence.

${ }^{3}$ Life Technologies Corp. (Grand Island, NY).

${ }^{4}$ Endogenous controls.

plasma NEFA concentration in 3 randomly selected cows was significantly greater at $0 \mathrm{~d}[0.70( \pm 0.15)$ $\mathrm{mEq} / \mathrm{L} ; P<0.014]$ than $-14 \mathrm{~d}[0.08( \pm 0.01) \mathrm{mEq} / \mathrm{L}]$ and $10 \mathrm{~d}[0.43( \pm 0.09) \mathrm{mEq} / \mathrm{L}]$.

\section{Plasma Oxylipid Profile}

Plasma oxylipid concentration differed across the periparturient period for 3 of the 23 oxylipids measured (Figures 1 and 2). Early lactation (10 d) was associated with increased 13-HODE relative to prepartum. Samples at $84 \mathrm{~d}$ had the greatest 9-HODE and 11-HETE concentrations. Plasma concentrations of 9-HODE were approximately 2-fold higher than 13-HODE. Both 9- and 13-HODE concentrations were approximately 10-fold higher than 11-HETE. No significant changes over time were observed in plasma concentrations of 20 oxylipids (Table 2). The limit of detection for oxylipids was $0.01 \mathrm{ng}$.

\section{Leukocyte mRNA Expression}

The inflammatory phenotype of peripheral leukocytes showed minor changes across the period of study. The expressions of 15-LOX1 and 15-hydroxyprostaglandin dehydrogenase mRNA in peripheral leukocytes were decreased significantly at $10 \mathrm{~d}$ postpartum, relative to prepartum samples, and also relative to 84-d samples for 15-LOX1 (Figure 3). The expression of $I L-12 B$ mRNA was significantly increased at parturition and $10 \mathrm{~d}$, relative to 28 -d samples (Figure 4). No significant changes were observed in the gene expression of $I L-10$, inducible nitric oxide synthase 2 (NOS2), $I L-1 \beta, T N F-\alpha$, or $C O X 2$ during the entire experimental period.

\section{PBMC FAME Content}

The C18:2n-6 and C20:4n-6 FAME were consistently detected in PBMC, across all cows and sample periods. The concentrations of $\mathrm{C} 18: 2 \mathrm{n}-6$ and $\mathrm{C} 20: 4 \mathrm{n}-6$ were significantly increased at $10 \mathrm{~d}$ relative to prepartum samples (Figure 5). Peripheral blood mononuclear cell C20:5n-3 FAME was not detected in 20 of 35 PBMC samples. The mean $( \pm \mathrm{SE})$ C20:5n-3 FAME was 899 $( \pm 132)$ ng. The minimum mass of the C20:5n-3 FAME standard used and detected was $4 \mathrm{ng}$. The C22:6n-3 FAME was detected in 1 sample; therefore, no statistical analysis for this FAME was performed. The limit of

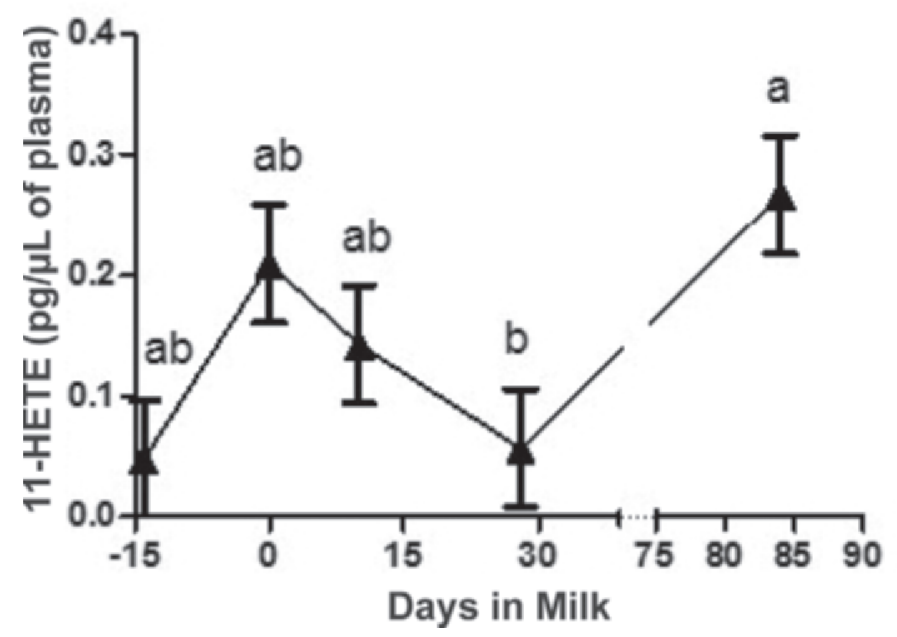

Figure 1. Plasma concentrations of arachidonic acid-derived oxylipid, 11-hydroxyeicosatetraenoic acid (11-HETE) changed across the periparturient period (reported as $\mathrm{LSM} \pm \mathrm{SE} ; P \leq 0.05$; differences are labeled with different letters ( $\mathrm{a}$ and $\mathrm{b}$ ); $\mathrm{n}=7$ ). 

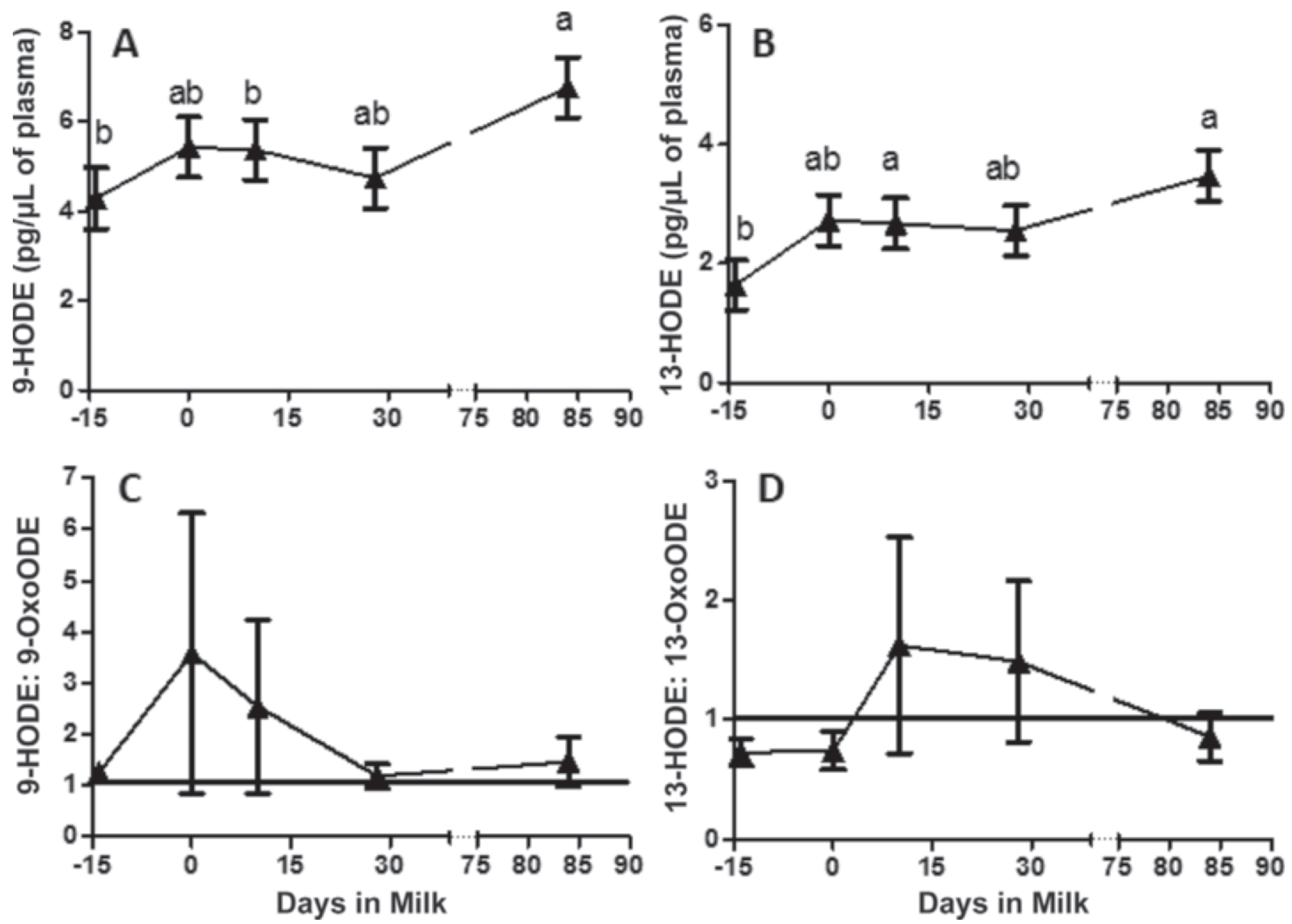

Figure 2. Plasma concentration of linoleic acid-derived oxylipids 9-hydroxyoctadecadienoic acid (9-HODE; A) and 13-HODE (B) changed in the periparturient period. The ratios of 9-HODE to 9-oxooctadecadienoic acid (9-OxoODE; C) and 13-HODE to 13-OxoODE (D) show increased variance in the early-lactation period and the ratio is higher for 9-isomers than 13-isomers at similar stages of lactation. The ratio of 13 -HODE to 13-OxoODE inverted in early lactation (D), indicating that mean 13-HODE concentrations exceeded mean 13-OxoODE concentrations in early lactation. Results are reported as $\mathrm{LSM} \pm \mathrm{SE}(P \leq 0.05$; differences are labeled with different letters $(\mathrm{a}$ and $\mathrm{b}) ; \mathrm{n}=7)$.

detection of the C22:6n-3 FAME standard was $0.57 \mathrm{ng}$. Samples contained a chromatogram peak at the identical retention time as $\mathrm{C} 22: 6 \mathrm{n}-3$ did in standards, but this peak was abundant in $239 \mathrm{amu}$, was not the mass spectra of C22:6n-3 or typical of any methyl ester, and was not identified. Fatty acid methyl ester C18:2n-6 was the only FAME of interest detected in cell-free control samples (mean \pm SE of 5 extraction batches $=$ $3,912 \pm 860 \mathrm{ng})$.

\section{Statistical Relationships}

No significant correlations existed between C18:2n-6, C20:4n-6, or C20:5n-3 in PBMC and plasma oxylipids. Among the leukocyte genes assessed, $I L-12 B, I L-1 B$, COX2, and NOS2 expression was associated with plasma oxylipids (Table 3). Expression of hydroxyprostaglandin dehydrogenase was associated with C20:5n-3 concentrations $(\mathrm{r}=-0.75 ; P=0.0052)$.

\section{DISCUSSION}

This study showed for the first time how concentrations of select pro- and antiinflammatory plasma oxylipids change in dairy cows that successfully transitioned from late gestation to early lactation without clinical illness. Until now, only select bovine oxylipids were studied in physiological processes, such as luteolysis and maintenance of pregnancy (Lee et al., 2013; Skarzynski et al., 2013), and also in case-control studies of bovine pathology (Reinhold et al., 2000; Seals et al., 2002), but little was known about the relationships between 

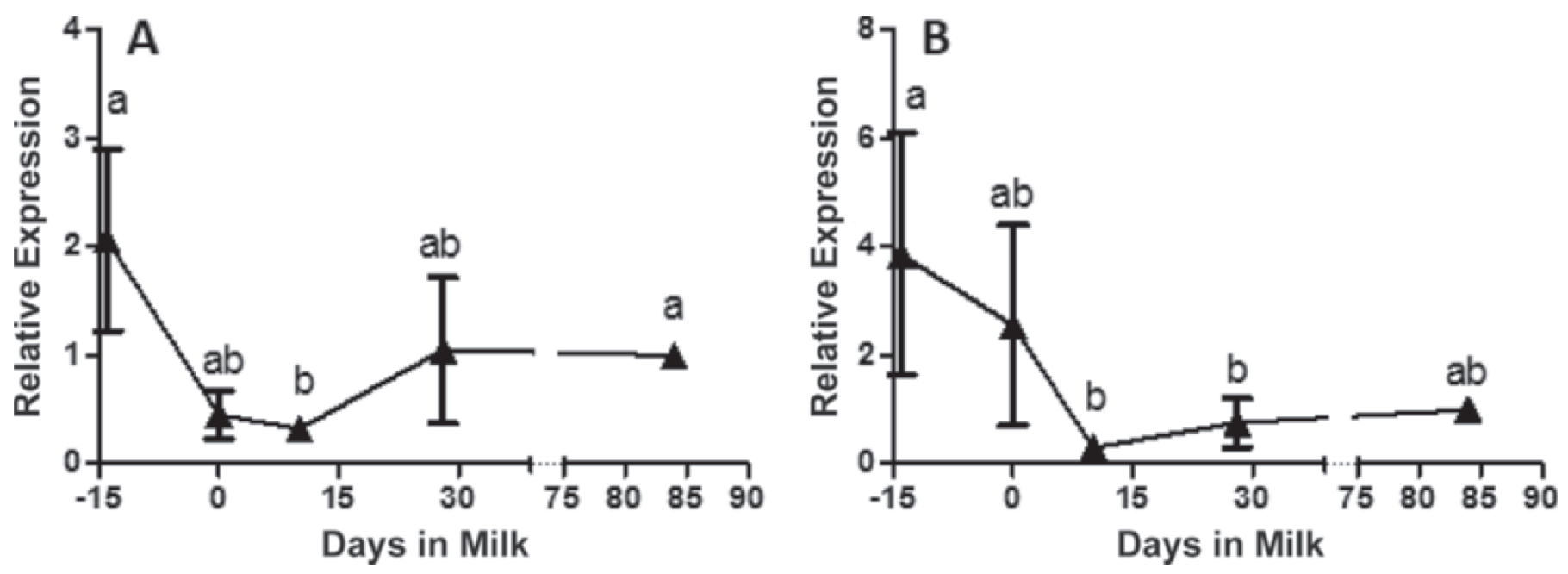

Figure 3. Relative $( \pm \mathrm{SE})$ 15-lipoxygenase 1 (15-LOX1; A) and 15-hydroxyprostaglandin dehydrogenase (HPGD; B) mRNA expression from peripheral leukocytes, calibrated to expression in 84-d samples $(P \leq 0.05$; differences are labeled with different letters $(\mathrm{a}$ and $\mathrm{b})$; $\mathrm{n}=7)$.

plasma oxylipids and peripheral leukocyte inflammatory responses. Leukocytes are a primary target for the actions of oxylipids, so changes in PBMC inflammatory gene expression in the absence of clinical disease may be due to the actions of these potent lipid mediators. Results from the current study revealed several notable features of the periparturient oxylipid profile. For example, hydroxyl forms of C18:2n-6 (13-HODE) was the most abundant plasma oxylipid, especially during early lactation. Several proinflammatory effects of HODE ex- ist, such as induction of adhesion molecule expression on human vascular tissue (Friedrichs et al., 1999). The HODE also were the most abundant oxylipids found in human atherosclerotic lesions (Gertow et al., 2011) and, therefore, have been investigated as potential contributors to chronic, uncontrolled inflammatory conditions. In contrast, HODE can be important activators of peroxisome proliferator-activated receptors (Nagy et al., 1998), which can lead to decreased expression of inflammation-based genes such as iNOS (Ricote et al.,

Table 2. Plasma oxylipids with stable concentration across the periparturient period (mean $\pm \mathrm{SE} ; \mathrm{pg} / \mu \mathrm{L} ; \mathrm{n}=7$ )

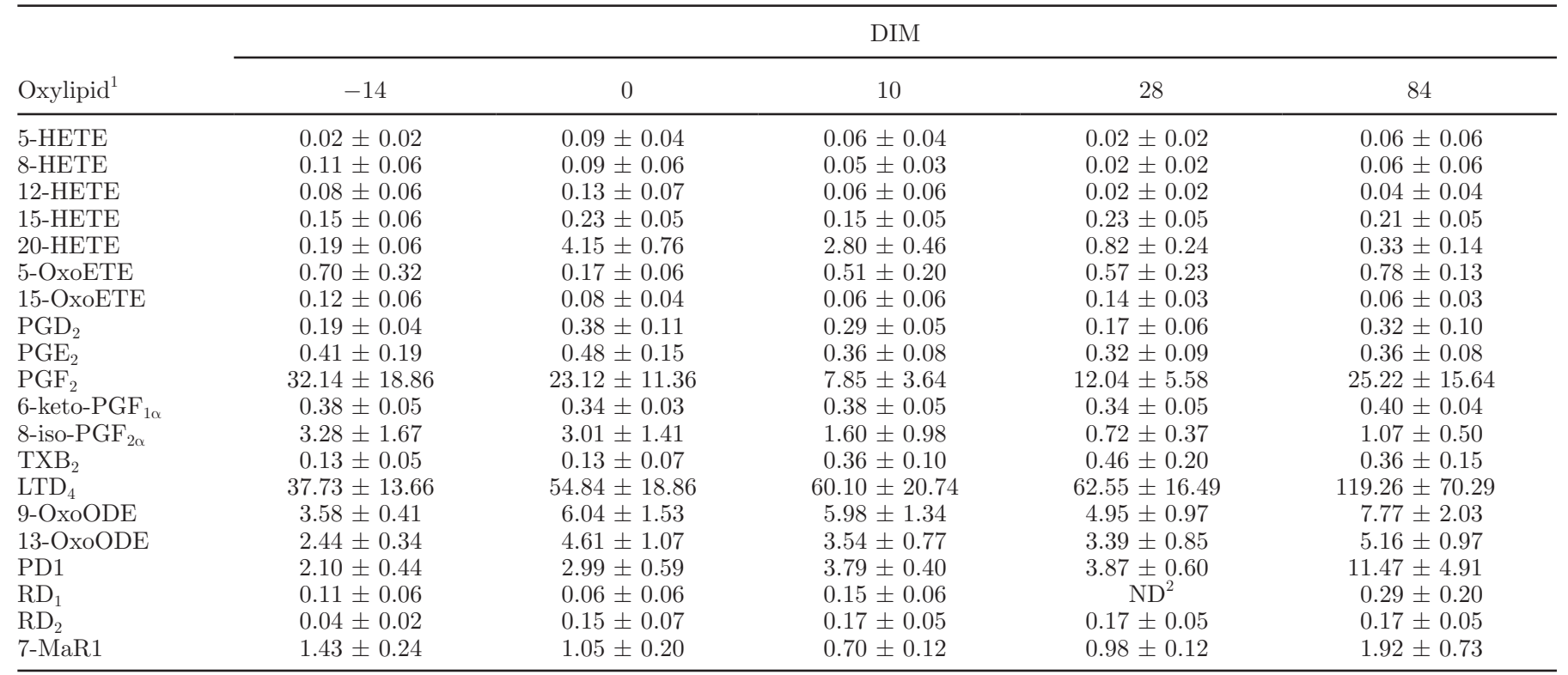

${ }^{1} \mathrm{HETE}=$ hydroxyeicosatetraenoic acid; OxoETE $=$ oxoeicosatetraenoic acid; $\mathrm{PG}=$ prostaglandin; TX $=$ thromboxane; LT $=$ leukotriene; OxoODE $=$ oxooctadecadienoic acid $; \mathrm{PD}=$ protectin $\mathrm{D} ; \mathrm{RD}=$ resolvin $\mathrm{D} ; \mathrm{MaR}=$ maresin.

${ }^{2} \mathrm{ND}=$ not detected. 


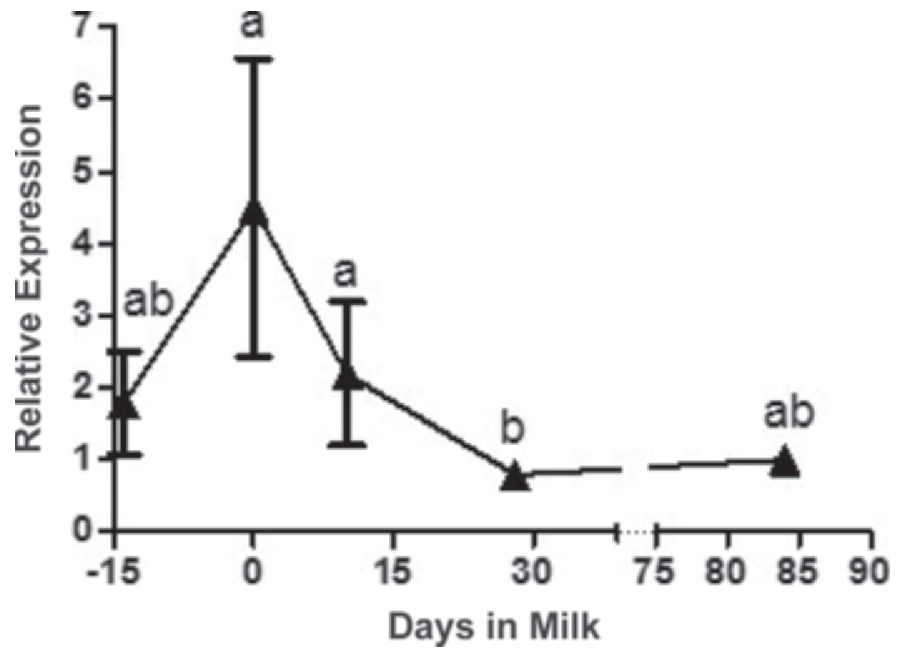

Figure 4. Relative $( \pm \mathrm{SE}) I L-12 B$ mRNA expression from peripheral leukocytes, calibrated to expression in 84-d samples $(P \leq 0.05$; differences are labeled with different letters $(\mathrm{a}$ and $\mathrm{b}) ; \mathrm{n}=7)$.

1998). Thus, the current literature suggests that HODE could be pro- or antiinflammatory oxylipids in different situations. The significance of enhanced HODE biosynthesis during the periparturient period on bovine inflammatory responses is not known. The possibility that HODE may contribute to dysfunctional inflammatory reactions in early-lactation cows with metabolic or infectious diseases would be a logical question to ask in future studies.

The enhanced expression of HODE in periparturient cows could be due to several factors, including substrate availability. The substrate for HODE, C18:2n-6, increased in PBMC during early lactation (Figure 5).

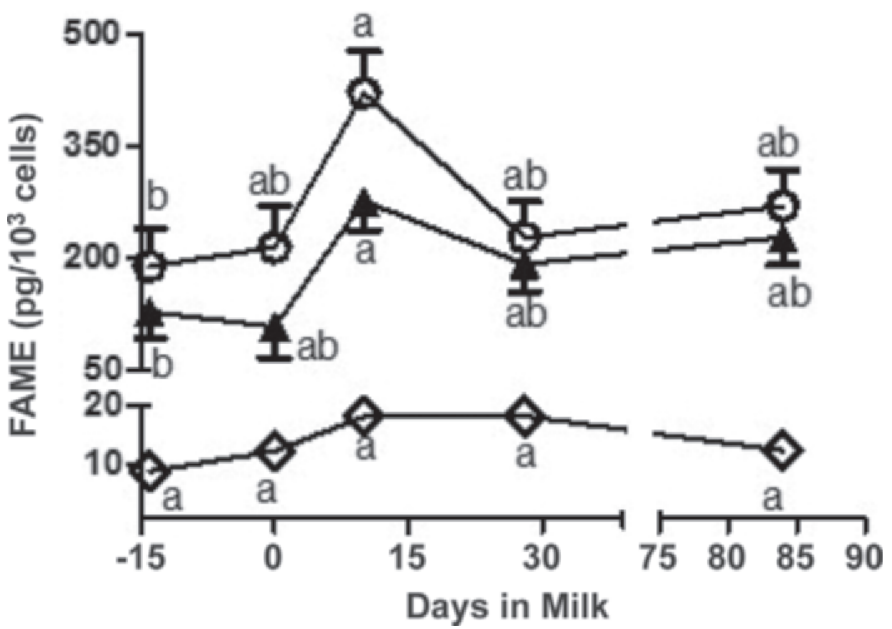

Figure 5. Linoleic (C18:2n-6; $\mathbf{\Delta})$ and arachidonic acid (C20:4n-6; O) concentrations in peripheral blood mononuclear cells increased in early lactation relative to prepartum samples, whereas eicosapentaenoic $(\mathrm{C} 20: 5 \mathrm{n}-3 ; \diamond)$ acid concentrations were unchanged. Results are reported as LSM $\pm \mathrm{SE}(P \leq 0.05$; differences are labeled with different letters $(\mathrm{a}$ and $\mathrm{b}) ; \mathrm{n}=7)$. FAME $=$ FA methyl ester.

These findings are consistent with earlier studies that reported an increase in plasma and liver C18:2n-6 concentrations of recently calved dairy cows (Contreras et al., 2010; Akbar et al., 2013). Both in vivo and in vitro studies support the contention that increased HODE biosynthesis is at least partly regulated by substrate availability. For example, increased human dietary C18:2n-6 intake is associated with increased plasma HODE concentration (Ramsden et al., 2012). Increased HODE biosynthesis was observed in cultured bovine endothelial cells exposed to a NEFA mixture with high

Table 3. Correlations between plasma oxylipid concentrations and peripheral leukocyte mRNA expression, adjusted for multiple tests

\begin{tabular}{llcc}
\hline Oxylipid $^{1}$ & Gene & $\begin{array}{c}\text { Pearson } \\
\text { coefficient }\end{array}$ & $P$-value \\
\hline PGE $_{2}$ & $I L-12 B$ & 0.58 & $<0.0001$ \\
LTD $_{4}$ & $I L-12 B$ & 0.55 & 0.013 \\
$\mathrm{PGD}_{2}$ & $I L-12 B$ & 0.48 & 0.046 \\
9-HODE & $I L-12 B$ & -0.52 & 0.013 \\
$13-\mathrm{HODE}$ & $I L-12 B$ & -0.55 & 0.013 \\
$5-\mathrm{OxoETE}$ & $I L-12 B$ & -0.64 & $<0.0001$ \\
$\mathrm{PGF}_{2}$ & $I L-12 B$ & -0.66 & $<0.0001$ \\
8-iso-PGF & $I L-12 B$ & -0.69 & $<0.0001$ \\
9-HODE & NOS2 & 0.63 & $<0.0001$ \\
$13-\mathrm{HODE}$ & NOS2 & 0.63 & $<0.0001$ \\
$\mathrm{PGF}_{2}$ & NOS2 & 0.63 & $<0.0001$ \\
8-iso-PGF & NOS2 & 0.62 & 0.0001 \\
5-OxoETE & NOS2 & 0.59 & $<0.0001$ \\
$15-\mathrm{HETE}$ & NOS2 & 0.53 & 0.037 \\
TXB $_{2}$ & COX2 & -0.57 & -0.49 \\
TXB $_{2}$ & $I L-1 B$ & -0.49 & \\
\hline
\end{tabular}

${ }^{1} \mathrm{PG}=$ prostaglandin; $\mathrm{LT}=$ leukotriene; HODE $=$ hydroxyoctadecadienoic acid; OxoETE $=$ oxoeicosatetraenoic acid; HETE = hydroxyeicosatetraenoic acid; TX = thromboxane. 
C18:2n- 6 content that is typically found in bovine plasma during the periparturient period (Contreras et al., 2012b). Therefore, increased plasma HODE concentration may be a reflection of increased tissue, leukocyte, or plasma contents of C18:2n-6. The tissue and cellular sources of plasma HODE measured in this study were not assessed. Oxidation of C18:2n-6 may occur in leukocytes or other cell types by COX, LOX, epoxygenase, and nonenzymatic oxidation. Previous studies showed increased COX2 and 15-LOX1 mRNA and COX2 protein expression in bovine vascular endothelial cells in response to NEFA typical of those present in bovine plasma during the periparturient period (Contreras et al., 2012b). Chemical inhibition of COX and 15-LOX enzymes, however, did not abrogate endothelial HODE biosynthesis from NEFA and it was suggested that nonenzymatic oxidation of plasma $\mathrm{C} 18: 2 \mathrm{n}-6$ could contribute to endothelial cell production of plasma HODE (Contreras et al., 2012a). Reduced transcript expression of leukocyte 15-LOX1 in this study also may suggest a decreased capacity for the enzymatic oxidation of $\mathrm{C} 18: 2 \mathrm{n}-6$ in early lactation. Identifying the primary cellular sources of HODE and the mechanism of oxidation could have future implications of how to not only regulate its biosynthesis, but also influence the relative contribution to inflammatory responses.

The ratios of HODE to OxoODE reveal changes to $\mathrm{C} 18: 2 \mathrm{n}-6$ metabolism in early lactation. Mean 13-HODE-to-13-OxODE ratios (Figure 2d) indicate lesser abundance of the ketone derivative than hydroxyl derivative of $\mathrm{C} 18: 2 \mathrm{n}-6$ during the first weeks of lactation (ratio $>1.0$ ) relative to prepartum, parturition, and $84 \mathrm{~d}$ (ratio <1.0). Moreover, the range of both 13-HODE-to-13-OxODE and 9-HODE-to-9-OxoODE ratios (Figure 2c) were greatest in early lactation. Hydroxyoctadecadienoic acid is the reduced product of HPODE, which is more stable and can be converted into OxoODE by dehydrogenation (Ramsden et al., 2012). The extent of HPODE metabolism is directly associated with antiinflammatory potential (Nagy et al., 1998; Friedrichs et al., 1999); therefore, increasing HODE-to-OxoODE ratios may indicate a change in the net effect of C18:2n-6-derived oxylipids on inflammatory pathways. If future studies prove the HODEto-OxoODE ratio to be influential in bovine inflammatory responses, then the precise pathways by which HODE are degraded in cows should be investigated as a potential target of inflammatory disease intervention (Hamberg and Samuelsson, 1980; Yoshida et al., 2013).

Temporal changes in the plasma oxylipid profile can provide some insight as to how bovine leukocytes may respond within that microenvironment. Whereas the HODE increased during early lactation, it is important to also note those oxylipids that did not change concen- tration in this study. For example, the steady-state biosynthesis of certain antiinflammatory oxylipids could influence leukocyte phenotype when considered as a key component of the overall oxylipid profile. In this study, several potent antiinflammatory oxylipids (PD1, RD1, RD2, and 7-MaR1) did not significantly change throughout the experimental period in the absence of clinical disease. Several recent studies documented the significance of these oxylipids in resolving inflammation and restoring tissue to normal function following infections (Serhan et al., 2008; Serhan and Petasis, 2011). The precise role of these antiinflammatory oxylipids on bovine leukocytes during the periparturient period is not known. The present study does, however, provide baseline information of the overall oxylipid profile in cows that successfully transition into lactation without succumbing to disease. Plasma oxylipids will likely differ by health state, as oxylipid enzyme expression is influenced by disease (Schmitz et al., 2004).

Correlations between plasma oxylipids and peripheral leukocyte mRNA expression were conducted to assess the potential impact that certain proinflammatory and antiinflammatory bovine oxylipids may have in the absence of clinical disease. In the present study, no dramatic changes were observed in several markers used previously to assess leukocyte proinflammatory responses during the periparturient period. This is in contrast to previous studies that documented significant cytokine gene expression in PBMC obtained from periparturient cows subjected to metabolic, environmental, or microbial challenge (Sordillo et al., 1995; Moyes et al., 2010; Tao et al., 2013). The present study, however, used healthy animals and the results are consistent with previous reports noting no change in PBMC proinflammatory cytokine mRNA expression in periparturient cows that remain free of clinical disease (Ohtsuka et al., 2006). Pearson coefficients did identify several correlations between oxylipids and PBMC gene expression, although no clear conclusion can be drawn from the inconsistent findings (Table 3 ). Although some oxylipids with known proinflammatory functions $\left(\mathrm{PGE}_{2}\right.$ and $\left.\mathrm{LTD}_{4}\right)$ were positively correlated with proinflammatory gene expression, as would be expected, several instances existed where proinflammatory oxylipids $\left(\mathrm{TXB}_{2}, 9-\mathrm{HODE}\right.$, and 13-HODE) were negatively correlated with the proinflammatory markers (Table 3). One explanation is that cytokine expression and proinflammatory oxylipid biosynthesis may form negative feedback loops with each other. Expression of epoxygenase enzymes, for example, can be suppressed by TNF- $\alpha$ (Bell, 2011; Bell and Strobel, 2012). Another possibility is that certain oxylipids may be more effective in controlling leukocyte inflammatory responses than other lipid mediators within the profile. 
Without conducting more controlled cause-effect studies, it is not possible to determine which oxylipids may be the most potent in regulating PBMC gene responses. Based on the findings presented in this study, however, it is clear that the oxylipid network is complex and the relative impact on leukocyte responses during the periparturient period will likely be determined by the relative composition of the oxylipid profile.

\section{CONCLUSIONS}

In conclusion, this study showed for the first time how concentrations of a select group of oxylipids change during the periparturient period in healthy animals. The most abundant oxylipids during early lactation were those derived from C18:2n-6 and C20:4n-6, with significant increases in their respective hydroxyl products (HODE and 11-HETE) as lactation progressed. Although plasma oxylipids are likely derived from many cellular sources, an interesting observation in this study was that the significant increases in HODE and 11-HETE corresponded to significant increases in PBMC content of their respective PUFA substrates (C18:2n-6 and C20:4n-6). These findings suggest that it may be feasible to manipulate oxylipid concentrations during the periparturient period by altering the dietary content of available PUFA that can be metabolized through various peroxidation pathways. Future studies that focus on how individual oxylipids may directly affect the proinflammatory responses of bovine leukocytes would provide the foundation for targeted therapies used to optimize innate immune defenses during the periparturient period.

\section{ACKNOWLEDGMENTS}

The authors acknowledge the resources and staff of the Michigan State University Research Technology Support Facility Mass Spectrometry Core (East Lansing), especially Dan Jones and Scott Smith. The authors also acknowledge Jeff Gandy and Edward Kabara (both from College of Veterinary Medicine, Michigan State University, East Lansing), Juan Steibel (College of Agriculture and Natural Resources, Michigan State University), and the owners and staff of the herd for their assistance. This work was funded, in part, through grants (2011-67015-30179 and 2012-67011-20019) from the Agriculture and Food Research Initiative Competitive Grants Programs of the USDA National Institute for Food and Agriculture (Washington, DC) and by an endowment from the Matilda R. Wilson Fund (Detroit, MI).

\section{REFERENCES}

Akbar, H., E. Schmitt, M. A. Ballou, M. N. Corrêa, E. J. DePeters and J. J. Loor. 2013. Dietary lipid during late-pregnancy and early-lactation to manipulate metabolic and inflammatory gene network expression in dairy cattle liver with a focus on PPARs. Gene Regul. Syst. Bio. 7:103-123.

Altmann, R., M. Hausmann, T. Spöttl, M. Gruber, A. W. Bull, K. Menzel, D. Vogl, H. Herfarth, J. Schölmerich, W. Falk, and G. Rogler. 2007. 13-Oxo-ODE is an endogenous ligand for PPAR $\gamma$ in human colonic epithelial cells. Biochem. Pharmacol. 74:612-622.

Bell, J. C. 2011. Expression and regulation of human cytochrome P450 $4 \mathrm{~F}$ isoforms in tissue samples and under TNF- $\alpha$ challenges. $\mathrm{PhD}$ Diss. Graduate School of Biomedical Sciences, University of Texas, Houston.

Bell, J. C., and H. W. Strobel. 2012. Regulation of cytochrome P450 4 F11 by nuclear transcription factor- $\kappa$ B. Drug Metab. Dispos. 40:205-211.

Bligh, E. G., and W. J. Dyer. 1959. A rapid method of total lipid extraction and purification. Can. J. Biochem. Physiol. 37:911-917.

Contreras, G. A., S. A. Mattmiller, W. Raphael, J. C. Gandy, and L. M. Sordillo. 2012a. Enhanced n-3 phospholipid content reduces inflammatory responses in bovine endothelial cells. J. Dairy Sci. 95:7137-7150.

Contreras, G. A., W. Raphael, S. A. Mattmiller, J. Gandy, and L. M. Sordillo. 2012b. Nonesterified fatty acids modify inflammatory response and eicosanoid biosynthesis in bovine endothelial cells. J. Dairy Sci. 95:5011-5023.

Contreras, G. A., N. J. O'Boyle, T. H. Herdt, and L. M. Sordillo. 2010 Lipomobilization in periparturient dairy cows influences the composition of plasma nonesterified fatty acids and leukocyte phospholipid fatty acids. J. Dairy Sci. 93:2508-2516.

Farney, J. K., L. K. Mamedova, and J. F. Coetzee. BKuKanich, L. M., S. K. Sordillo, J. E. Stoakes, L. C. Minton, Hollis, and B. J. Bradford. 2013. Anti-inflammatory salicylate treatment alters the metabolic adaptations to lactation in dairy cattle. Am. J. Physiol. Regul. Integr. Comp. Physiol. 305:R110-R117. http:// dx.doi.org/10.1152/ajpregu.00152.2013.

Folch, J., M. Lees, and G. Sloane-Stanley. 1957. A simple method for the isolation and purification of total lipids from animal tissues. J. Biol. Chem. 226:497-509

Friedrichs, B., M. Toborek, B. Hennig, L. Heinevetter, C. Müller, and R. Brigelius-Flohé. 1999. 13-HPODE and 13-HODE modulate cytokine induced expression of endothelial cell adhesion molecules differently. Biofactors 9:61-72.

Gertow, K., E. Nobili, L. Folkersen, J. W. Newman, T. L. Pedersen, J. Ekstrand, J. Swedenborg, H. Kühn, C. E. Wheelock, G. K. Hansson, U. Hedin, J. Z. Haeggström, and A. Gabrielsen. 2011. 12- and 15-lipoxygenases in human carotid atherosclerotic lesions: Associations with cerebrovascular symptoms. Atherosclerosis 215:411-416.

Hamberg, M., and B. Samuelsson. 1980. Stereochemistry in the formation of 9-hydroxy-10,12-octadecadienoic acid and 13-hydroxy-9,11octadecadienoic acid from linoleic acid by fatty acid cyclooxygenase. Biochim. Biophys. Acta 617:545-547.

Lee, J., J. A. McCracken, S. K. Banu, and J. A. Arosh. 2013. Intrauterine inhibition of prostaglandin transporter protein blocks release of luteolytic $\mathrm{PGF}_{2 \alpha}$ pulses without suppressing endometrial expression of estradiol or oxytocin receptor in ruminants. Biol. Reprod. 89:27. http://dx.doi.org/10.1095/biolreprod.112.106427.

Livak, K. J., and T. D. Schmittgen. 2001. Analysis of relative gene expression data using real-time quantitative PCR and the $2^{-\Delta \Delta \mathrm{CT}}$ method. Methods 25:402-408.

Moyes, K. M., J. K. Drackley, D. E. Morin, and J. J. Loor. 2010. Greater expression of TLR2, TLR4, and IL6 due to negative energy balance is associated with lower expression of $H L A-D R A$ and $H L A-A$ in bovine blood neutrophils after intramammary mastitis challenge with Streptococcus uberis. Funct. Integr. Genomics 10:53-61. 
Nagy, L., P. Tontonoz, J. G. A. Alvarez, H. Chen, and R. M. Evans. 1998. Oxidized LDL regulates macrophage gene expression through ligand activation of PPAR $\gamma$. Cell 93:229-240.

Nakamura, M., and T. Shimizu. 2011. Leukotriene receptors. Chem. Rev. 111:6231-6298.

Norling, L. V., J. Dalli, R. J. Flower, C. N. Serhan, and M. Perretti. 2012. Resolvin D1 limits polymorphonuclear leukocyte recruitment to inflammatory loci: Receptor-dependent actions. Arterioscler. Thromb. Vasc. Biol. 32:1970-1978.

Ohtsuka, H., C. Watanabe, M. Kohiruimaki, T. Ando, D. Watanabe, M. Masui, T. Hayashi, R. Abe, M. Koiwa, S. Sato, and S. Kawamura. 2006. Comparison of two different nutritive conditions against the changes in peripheral blood mononuclear cells of periparturient dairy cows. J. Vet. Med. Sci. 68:1161-1166.

Palmquist, D. L., and T. C. Jenkins. 2003. Challenges with fats and fatty acid methods. J. Anim. Sci. 81:3250-3254.

Pinedo, P. J., A. De Vries, and D. W. Webb. 2010. Dynamics of culling risk with disposal codes reported by Dairy Herd Improvement dairy herds. J. Dairy Sci. 93:2250-2261.

Poulsen, R. C., K. H. Gotlinger, C. N. Serhan, and M. C. Kruger. 2008. Identification of inflammatory and proresolving lipid mediators in bone marrow and their lipidomic profiles with ovariectomy and omega-3 intake. Am. J. Hematol. 83:437-445.

Ramsden, C. E., A. Ringel, A. E. Feldstein, A. Y. Taha, B. A. MacIntosh, J. R. Hibbeln, S. F. Majchrzak-Hong, K. R. Faurot, S. I. Rapoport, Y. Cheon, Y.-M. Chung, M. Berk, and J. D. Mann. 2012. Lowering dietary linoleic acid reduces bioactive oxidized linoleic acid metabolites in humans. Prostaglandins Leukot. Essent. Fatty Acids 87:135-141.

Raphael, W., and L. M. Sordillo. 2013. Dietary polyunsaturated fatty acids and inflammation: The role of phospholipid biosynthesis. Int. J. Mol. Sci. 14:21167-21188.

Reinhold, P., G. Becher, and M. Rothe. 2000. Evaluation of the measurement of leukotriene B4 concentrations in exhaled condensate as a noninvasive method for assessing mediators of inflammation in the lungs of calves. Am. J. Vet. Res. 61:742-749.

Ricote, M., A. C. Li, T. M. Willson, C. J. Kelly, and C. K. Glass. 1998. The peroxisome proliferator-activated receptor- $\gamma$ is a negative regulator of macrophage activation. Nature 391:79-82.

Schmitz, S., M. W. Pfaffl, H. H. D. Meyer, and R. M. Bruckmaier. 2004. Short-term changes of mRNA expression of various inflam- matory factors and milk proteins in mammary tissue during LPSinduced mastitis. Domest. Anim. Endocrinol. 26:111-126.

Seals, R. C., I. Matamoros, and G. S. Lewis. 2002. Relationship between postpartum changes in 13, 14-dihydro-15-keto-PGF ${ }_{2 \alpha}$ concentrations in Holstein cows and their susceptibility to endometritis. J. Anim. Sci. 80:1068-1073.

Serhan, C. N., N. Chiang, and T. E. Van Dyke. 2008. Resolving inflammation: Dual anti-inflammatory and pro-resolution lipid mediators. Nat. Rev. Immunol. 8:349-361.

Serhan, C. N., and N. A. Petasis. 2011. Resolvins and protectins in inflammation resolution. Chem. Rev. 111:5922-5943.

Serhan, C. N., R. Yang, K. Martinod, K. Kasuga, P. S. Pillai, T. F. Porter, S. F. Oh, and M. Spite. 2009. Maresins: Novel macrophage mediators with potent antiinflammatory and proresolving actions. J. Exp. Med. 206:15-23.

Shuster, D. E., E. K. Lee, and M. E. Kehrli Jr. 1996. Bacterial growth, inflammatory cytokine production, and neutrophil recruitment during coliform mastitis in cows within ten days after calving, compared with cows at midlactation. Am. J. Vet. Res. 57:1569 1575 .

Skarzynski, D. J., K. K. Piotrowska-Tomala, K. Lukasik, A. Galvão, S. Farberov, Y. Zalman, and R. Meidan. 2013. Growth and regression in bovine corpora lutea: Regulation by local survival and death pathways. Reprod. Domest. Anim. 48(Suppl. 1):25-37.

Smith, W. L., Y. Urade, and P.-J. Jakobsson. 2011. Enzymes of the cyclooxygenase pathways of prostanoid biosynthesis. Chem. Rev. 111:5821-5865.

Sordillo, L. M., G. M. Pighetti, and M. R. Davis. 1995. Enhanced production of bovine tumor necrosis factor- $\alpha$ during the periparturient period. Vet. Immunol. Immunopathol. 49:263-270.

Sordillo, L. M., and W. Raphael. 2013. Significance of metabolic stress, lipid mobilization, and inflammation on transition cow disorders. Vet. Clin. North Am. Food Anim. Pract. 29:267-278.

Tao, S., E. E. Connor, J. W. Bubolz, I. M. Thompson, B. C. do Amaral, M. J. Hayen, and G. E. Dahl. 2013. Short communication: Effect of heat stress during the dry period on gene expression in mammary tissue and peripheral blood mononuclear cells. J. Dairy Sci. 96:378-383.

Yoshida, Y., A. Umeno, and M. Shichiri. 2013. Lipid peroxidation biomarkers for evaluating oxidative stress and assessing antioxidant capacity in vivo. J. Clin. Biochem. Nutr. 52:9-16. 